Fig. 3. Learning curves for four hearing categories with List 1 .

the consistent list. However, the predicted interaction between pairings and hearing was supported by the slopes of the functions relating performance to PTA, this being zero for the inconsistent list and significantly positjve for the consistent list.

Both normal-hearing Grade $4 \mathrm{Ss}$ in group testing and the $0.25 \mathrm{~dB}$ hearing-loss Ss in individual testing failed to perform differently on the two lists. Thus, the anticipated interference effect with the inconsistent list, predicted on the basis of Dallett's results, did not hold for this study. A number of procedural differences between Dallett's study and the present experiment may account for this discrepancy. Perhaps the most critical difference lies in the age groupings used, college students vs Grade 4 children. It may be that the results obtained by Dallett cannot be generalized to younger Ss. However, the fact that children with severe hearing losses performed differently suggests that this explanation is not sufficient. To find hearing-handicapped children performing better than normals on any verbal task is contrary to all previous evidence and indicates that something about the materials themselves produced the differential performance.

The most significant finding emerging from this study is the fact just mentioned, that a hearing loss seemed to insure a trend to better performance, at least on the consistent list. This result, coupled with a clear distinction in the rate of learning that same list by Ss with and without significant hearing losses, provides additional support for the basic hypothesis in this experiment.

It had been postulated that normal-hearing and hearing-impaired differ in the way they manipulate verbal material internally. Certainly, the data from the consistent list indicate that the greater the hearing loss, the less interference obtained from acoustically similar words. Why this same effect was not noted with List I is not fully understood. The same words were used in either list and interference from acoustic similarity was found with both sets of pairings by Dallett. Thus, reduction in interference was expected on both lists with hearing-handicapped children but was not obtained.

On the basis of these results, one may conjecture that the hearing-loss Ss use physical appearance of the printed words as a primary dimension for encoding in contrast to the normal-hearing Ss' use of the implicit acoustic characteristics of the materials. Thus, the hearing-handicapped were able to circumvent the source of interference. The better performance on

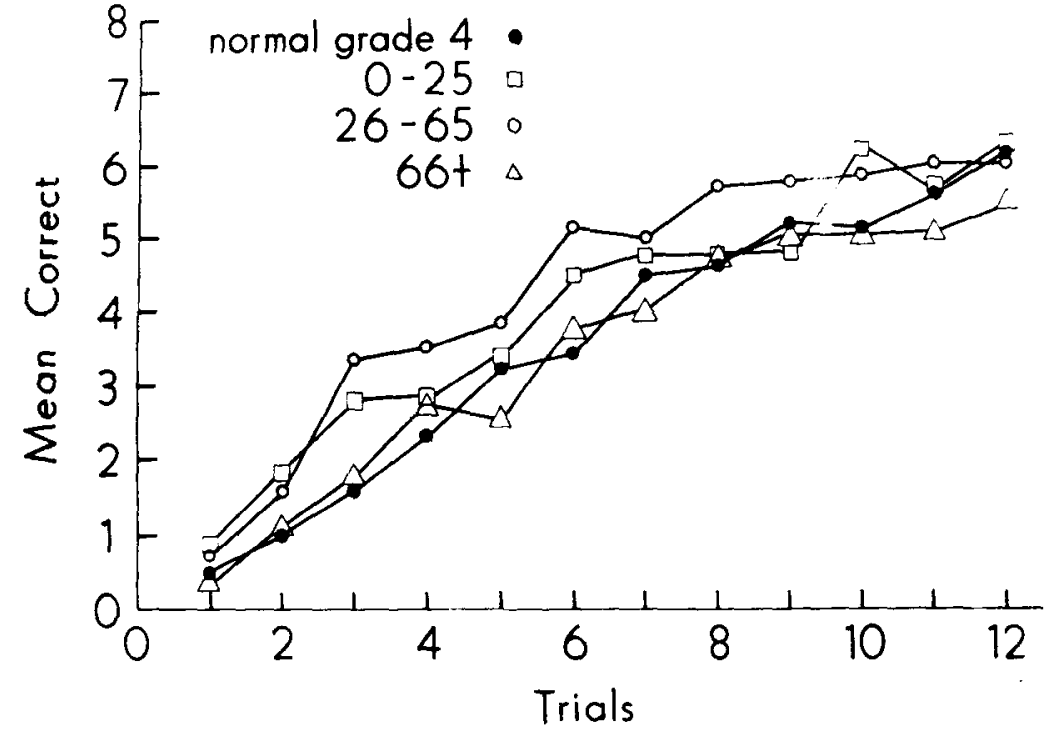

the consistent list by this group suggests that they were able to use the rhyming quality as a cue to aid learning. This facilitation would have to come from use of the auditory characteristics of the materials as a secondary attribute for encoding, since primary attention to this dimension would result in response generalization and interference. Thus, it may be that, to the normal-hearing child, a word is "thought of" first as a pattern of sounds and then as a set of orthographic symbols. In contrast, to a person with a congenital hearing loss, a word is first responded to as a set of letters and then, secondarily, as a pattern of phonemes, with the latter representing a learned response acquited through auditory training. Ultimately, of course, both kinds of Ss "think of" a word in terms of its meaning.

\section{REFERENCES}

BLANTON, R. L., \& NUNNALLY, J. C Retention of trigrams by deaf and hearing subjects as a function of pronunciability. Journal of Verbal Learning \& Verbal Behavior $1967,6,428-431$.
BLANTON, R. L., \& ODOM, P. B. Some possible interference and facilitation effects of pronunciability. Journal of Verbal Learning \& Verbal Behavior, 1968, 7, 844-846.

CONRAD, R., \& RUSH, M. L. On the nature of short-term memory encoding by the deaf. Journal of Speech \& Hearing Disorders, 1965 , 30, 336-343.

DALLETT, K. M. The effects of within-list and between-list acoustic similarity on the leaming and retention of paired associates. Joumal of Experimental Psychology, 1966, 72, 667-677.

ODOM, P. B., \& BLANTON, R. L. Phrase-learning in deaf and hearing subjects. Journal of Speech \& Hearing Research, 1967, 10,600-605.

THORNDIKE, E. L., \& LORGE, I. The teacher's word book of 30,000 words. New York: Bureau of Publications, Teachers College, Columbia University, 1944.

YOUNISS, J. Concept transfer as a function of shifts, age, and deafness. Child Development, $1964,35,695-700$.

\section{NOTE}

1. The work reported herein was performed pursuant to Grant No. OEG-0-8-070837-1858 from the U.S. Office of Education, Department of Health, Education, and Welfare.

\title{
Short-term memory encoding strategies of the deaf!
}

\section{JOHN L. LOCKE, ${ }^{2}$ University of Illinois, Champaign, Ill. 61820}

Deaf Ss, using an $A B X$ procedure, evaluated nine consonant letters in terms of the subjective kinesthetic similarity of their dactylic representations. Ranked data were compared to short-term memory recall errors for the same stimuli in a similar group of deaf $S s$ (Conrad \& Rush, 1965). Findings suggest that deaf $S s$ do not encode orthographic stimuli with a dactylo-kinesthetic system exclusively, if at all.

A series of experiments (Conrad, 1962, 1963; Wickelgren, 1965a, b, c) has established that short-term memory (STM) errors in verbal learning are predictable on the basis of the phonetic configuration of the stimulus items, regardless of whether the mode of presentation is auditory or visual. Apparently, Ss somehow convert a strictly visual language stimulus, such as an 
Table I

Ranked Recall Errors ${ }^{a}$ and Kinesthetic Similarity Judgments ${ }^{b}$ for Nine Consonant Letters

\begin{tabular}{|c|c|c|c|c|c|c|c|c|c|c|c|c|c|c|c|c|c|c|c|}
\hline \multirow{3}{*}{$\begin{array}{c}\text { Stimulus } \\
\text { Gesture }\end{array}$} & \multicolumn{9}{|c|}{ Recall Errors } & \multirow{3}{*}{$\begin{array}{l}\text { Stimulus } \\
\text { Gesture }\end{array}$} & \multicolumn{9}{|c|}{ Kinesthetic Similarity Judgments } \\
\hline & \multirow[b]{2}{*}{$\mathrm{B}$} & \multicolumn{6}{|c|}{ Letter Response } & \multirow[b]{2}{*}{$\mathrm{X}$} & \multirow[b]{2}{*}{$\mathrm{Y}$} & & \multicolumn{9}{|c|}{ Gesture Response } \\
\hline & & $\mathbf{F}$ & $\mathbf{K}$ & $\mathbf{p}$ & $\mathbf{R}$ & $\mathrm{T}$ & $\mathrm{V}$ & & & & $B$ & $\mathbf{F}$ & K & $\mathbf{P}$ & $\mathbf{R}$ & $\mathbf{T}$ & $\mathrm{V}$ & $x$ & $Y$ \\
\hline B & & 7 & 2.5 & 5 & 1 & 2.5 & 4 & 8 & 6 & B & & 3 & 4 & 7.5 & 5 & 2 & 6 & 7.5 & 1 \\
\hline $\mathrm{F}$ & 8 & & 3 & 2 & 1 & 7 & 4.5 & 4.5 & 6 & I & 1 & & 5 & 7.5 & 3 & 7.5 & 4 & 6 & 2 \\
\hline$K$ & 6 & 8 & & 4.5 & 4.5 & 7 & 2.5 & 2.5 & 1 & K & 3 & 8 & & 1 & 5 & 2 & 4 & 7 & 6 \\
\hline$P$ & 6 & 8 & 7 & & 1.5 & 4.5 & 3 & 4.5 & 1.5 & $\mathrm{P}$ & 5 & 7 & 1 & & 2 & 3.5 & 3.5 & 8 & 6 \\
\hline $\mathrm{R}$ & 6 & 7 & 8 & 1 & & 2 & 4.5 & 4.5 & 3 & $\mathrm{R}$ & 4.5 & 2.5 & 6 & 1 & & 2.5 & 4.5 & 8 & 7 \\
\hline$T$ & 7.5 & 6 & 4 & 2 & 5 & & 1 & 3 & 7.5 & $\mathrm{~T}$ & 3 & 5 & 2 & 4 & 6.5 & & 1 & 8 & 6.5 \\
\hline V & 8 & 6 & 5 & 7 & 4 & 1 & & 2 & 3 & $\mathrm{~V}$ & 3 & 6 & 5 & 7 & 2 & 1 & & 8 & 4 \\
\hline$X$ & 6 & 4.5 & 7 & 8 & 3 & 4.5 & 1 & & 2 & $X$ & 8 & 5 & 1 & 7 & $\overline{6}$ & 2 & 4 & & 3 \\
\hline $\mathrm{Y}$ & 6 & 7 & 8 & 3 & 4.5 & 4.5 & 2 & 1 & & $\mathbf{Y}$ & 1.5 & 3.5 & 7.5 & 7.5 & 6 & 3.5 & 1.5 & 5 & \\
\hline
\end{tabular}

Note-In all cases, $\rho$ or $r>.05 . \quad a$ Adapted from Conrad and Rush (1965).

$b$ Based on gestures from the dactylic alphabet.

orthographic character, into its phonemic counterpart in speech and encode the phoneme in STM with reference to its motor and/or acoustic characteristics. Presumably, phonetic mediation yields a response-produced stimulus, perhaps through imagery or subvocalization, such that the stimulus is a letter and the stored response is a phoneme. In this perspective, only a part of one's phonology is subservient to the demands of verbal communication. A large measure of its function would be to provide the learner with an encoding process for storing language-related stimuli in STM.

How would Ss store verbal items if they were unaware of their phonetic features? How do the deaf, who essentially are aphonological, encode orthographic stimuli? Conrad \& Rush (1965) pursued this matter by studying the error patterns of deaf Ss for nine consonant letters. Forgetting appeared systematic but could not be attributed to either phonetic or visual confusion. How, then, do deaf Ss store printed verbal items?

Theoretically, they would have the potential of storing whatever cues were available to them via their response. Normal-hearing $S s$ respond to visually presented verbal stimuli with covert articulatory activity (Edfeldt, 1960; McGuigan, 1966). There is some suggestion that their deaf counterparts respond with covert dactylic (finger-spelling) activity (Novikova, 1961). Presumably, faint kinesthetic sensations arising from these gestures could provide the basis for subsequent recall from motor storage areas. Apparently, for Ss whose primary mode of communication is dactylic, the alphabet of 26 manual configurations constitutes their "phonology." Deaf Ss' recall errors would then be at least partially attributable to motor-trace interference provided by the availability of kinesthetically similar competing responses. Since Conrad \& Rush (1965) have determined the frequency of ccrtain orthographic errors by deaf $\mathrm{Ss}$, the remaining question, now, is which of the dactylic gestures are kinesthetically most similar and, therefore, likely to be confused in the case of dactylic rehearsal.

\section{PROCEDURE}

Following an $A B X$ paradigm, Ss compared each of nine consonant letters with all possible pairings from the remaining eight on the basis of the subjective kinesthetic similarity of their dactylic representations. Each finger-spelled consonant served as the stimulus or $\mathrm{X}$ item once, resulting in a total of $252(9 \times 28)$ judgments. Instructions, communicated by pantomime, sign-language, and finger-spelling, were for Ss to compare only the "feel" of the letters' dactylic gestures, keeping the participating hand out of sight, and to record the letter whose finger-spelling was more similar to the stimulus letter. The task was completed in a single $90-\mathrm{min}$ session.

\section{MATERIALS}

The nine consonants were $B, F, K, P, R$, $T, V, X$, and $Y$, selected so kinesthetic-similarity data could be compared to STM-error data for these same letters, reported by Conrad \& Rush (1965). Ss were given a pretest opportunity to practice the $A B X$ procedure with nine nontest letters.

Twenty-one students in a residential school for the deaf, all highly proficient finger-spellers, volunteered to serve. Due to occasional misunderstanding and isolated S notational errors, data for any particular letter derives from subgroups of 13-16 Ss whose ages ranged from 15 to 23 years. Ss, like those in the Conrad \& Rush (1965) study, used standard finger-spelling gestures.

\section{RESULTS}

Data from this experiment and from Conrad \& Rush's (1965) study (Table 1) were analyzed for each letter by rank-correlation methods. All nine correlations were low and nonsignificant. DISCUSSION

Failure to find significant correlations between kinesthetic-similarity judgments and STM-recall errors for the same letters suggests, somewhat by default, the need to examine visual-encoding processes in greater detail. The more common error responses in Conrad \& Rush's (1965) experiment do seem, quite subjectively, to bear a visual resemblance to their stimuli (e.g., $R / B, Y / K, P / R, V / X, X / Y$ ). There is, of course, the possibility that kinesthetic similarity judgments based on overt dactylic gestures differ qualitatively from confusions arising from covert gestures. Or perhaps deaf Ss use idiosyncratic, or at least various, rehearsal and encoding procedures.

NRAD, R. An association between memory errors and errors due to acoustic masking of speech. Nature, 1962, 193, 1314-1315.

CONRAD, R. Acoustic confusions and memory span for words. Nature, 1963, 197, $1029-1030$.

CONRAD, R., \& RUSH, M. L. On the nature of short term memory encoding by the deaf. Journal of Speech \& Hearing Disorders, 1965 , $30,336-343$.

EDFELDT, A. W. Silent speech and silent reading. Chicago: University of Chicago Press, 1960.

McGUiGAN, F. J. Thinking: Studies of covert language processes. $\mathrm{New}$ York: Appleton-Century-Crofts, 1966.

NOVIKOVA, L. A. Electrophysiological investigation of speech. In F. J. McGuigan (Ed.), Thinking: Studies of covert language processes. New York: Appleton-CenturyCrofts, 1966. Pp. 104-121.

WICKELGREN, W. A. Acoustic similarity and intrusion errors in short-term memory. Journal of Experimental Psychology, 1965a, 70, 102-108.

WICKELGREN, W. A. Similarity and intrusions in short-tcrm memory for consonant-vowel digrams. Quarterly Journal of Experimental Psychology, 1965b, 17, 241-246.

WICKELGREN, W. A. Distinctive features and errors in short-term memory for English vowels. Journal of the Acoustical Society of America, $1965 \mathrm{c}, 38,583-588$. NOTE

1. The author acknowledges the assistance of Father Lawrence Murphy, Superintendent of the St. John's School for the Deaf, Milwaukee, and the students who served.

2. This paper was supported by Public Health Research Grant MH-07346 from the National Institute of Mental Health. 